\title{
O PAPEL DAS REUNIÕES RETROSPECTIVAS DO GERENCIAMENTO ÁGIL DE PROJETOS NA GESTÃO DO CONHECIMENTO: REFLEXÕES A PARTIR DE ANÁLISES MULTICASOS
}

Luís Fernando Magnanini de Almeida (luisfernando@dep.ufscar.br) - Departamento de Engenharia de Produção, UFSCar, Brasil.

Sérgio Luís da Silva (sergiol@ufscar.br) - Departamento de Ciência da Informação, UFSCar, Brasil.

\section{RESUMO}

$O$ "Paradoxo do Aprendizado" ilustra a dificuldade em se realizar a Gestão do Conhecimento em projetos. Se por um lado, devido aos seus resultados únicos, os projetos estimulam a criação do conhecimento, por outro, sua natureza temporária e exclusiva dificulta a sedimentação desses conhecimentos. Quando se utiliza o Gerenciamento Ágil de Projetos, esses desafios são potencializados, pois esses métodos são próprios para ambientes que demandam maior criação de conhecimentos. Por outro lado, neles a documentação é desestimulada e o cliente está inserido na equipe, que é autogerida, tudo isso contribuindo para a maior valorização do conhecimento tácito ao explícito, dificultando a captura e disseminação dos conhecimentos gerados. Para minimizar esses efeitos, o Gerenciamento Ágil de Projetos utiliza algumas práticas e rituais próprios, dentre eles, as reuniões retrospectivas. Foram estudados diferentes projetos em uma mesma organização, por meio do acompanhamento desse ritual e de entrevistas semiestruturadas com os participantes, constatando a sua efetiva contribuição para a Gestão do Conhecimento, assim como a melhora do desempenho das equipes. Averiguou-se que pequenas alterações nos procedimentos de execução dessas reuniões podem potencializar seus ganhos em termos de aprendizado e que, caso não seja adotada uma sistemática de melhoria contínua, pode-se regredir ao desempenho anterior.

Palavras-chave: Gerenciamento Ágil de Projetos, Gerenciamento de Projetos, Gestão do Conhecimento, Desenvolvimento de Produtos.

Área: Organização e gestão do conhecimento para o desenvolvimento de produtos

\section{INTRODUÇÃO}

A Gestão do Conhecimento (GC) nos projetos se torna imprescindível visto que o seu sucesso têm forte ligação com o conhecimento acumulado na empresa e nas competências individuais e coletivas da equipe que o executa, figurando dentre as razões primárias de insucesso em projetos a gestão pobre do conhecimento, comunicação deficiente e o uso inadequado das lições aprendidas (DE SOUZA; EVARISTO, 2006; FONG, 2008).

Apesar dessa ligação intrínseca, a gestão do conhecimento nesses ambientes apresenta dificuldades não triviais, sendo sintetizadas pelo "paradoxo de aprendizado em projetos", termo criado por Bakker et al. (2011), para ilustrar a aparente contradição imposta pela sua própria natureza. 
Por gerarem um resultado exclusivo (PMI, 2008), deve-se necessariamente criar novos conhecimentos para que se atinjam os objetivos de um projeto (FONG, 2008), sendo que durante o seu ciclo de vida são gerados aprendizados por meio da solução de problemas (AHERN; LEAVY; BYRNE, 2014a).

Contudo, por serem empreendimentos temporários, sua efemeridade e descontinuidade restringem a assimilação dos conhecimentos criados (BRESNEN et al., 2003; SWAN; SCARBROUGH; NEWELL, 2010). A necessidade de se ater ao prazo pré-estabelecido também contribui para que os projetos tenham o foco em entregas imediatas, o que pode levar a uma perda de conhecimento (WENGER, 2001; LINDNER; WALD, 2011), uma vez que outras atividades como as de gestão do conhecimento são deixadas em segundo plano ou, diversas vezes, nem executadas. Outro complicador é que, por serem únicos, os conhecimentos gerados nos projetos necessitam de informações de contexto para serem reaplicados, tendo a repetitividade e similaridade dos desafios como importante elemento para o reaproveitamento dos mesmos.

Quando se utiliza o Gerenciamento Ágil de Projetos (GAP), esses desafios se agravam, principalmente devido à priorização do uso do conhecimento em sua forma tácita (YANZER RIBEIRO; CABRAL; NOLL, 2014), o que requer uma nova abordagem com relação à GC, na qual o conhecimento que predominantemente existe na forma tácita está presente e é observado nas ações coletivas dos membros da equipe, que agem como um repositório de conhecimentos dinâmicos, o que aumenta o risco de serem perdidos quando esses membros deixam a organização (AMRITESH; MISRA, 2014).

Dentro dessa dinâmica as práticas e rituais do GAP são fundamentais para uma boa GC, em especial, a reunião retrospectiva que é o foco deste artigo. Esse ritual está diretamente ligado ao desenvolvimento iterativo e tem por finalidade contribuir para a melhoria contínua e fornecer um caminho para engajar os membros de uma equipe na otimização dos seus processos em resposta direta a problemas que eles enfrentaram (DAVIES; SEDLEY, 2009; RUBIN, 2012). Ela também minimiza os efeitos da pressão de tempo nos projetos e do foco no curto prazo, sendo um período pré-determinado para reflexão, análise e melhoria. Como é uma atividade em grupo e rica em interação entre os membros da equipe, contribui para a disseminação dos conhecimentos tácitos e para o aprendizado dos participantes, constituindo uma importante iniciativa de GC.

Frente a essa importância, foram acompanhadas reuniões retrospectivas de diferentes equipes de projeto de uma mesma empresa, analisando como diferentes dinâmicas de execução podem impactar na GC. Esses estudos de campo juntamente com a revisão de literatura permitiram a reflexão sobre os potenciais das reuniões retrospectivas na GC, e sobre como aumentar as trocas de conhecimentos tácitos e o aprendizado dos membros por meio dessas reuniões. Além da observação das reuniões, foram realizadas entrevistas semiestruturadas com alguns integrantes da equipe de projetos, assim como a análise dos documentos gerados.

\section{GESTÃO DO CONHECIMENTO NO GERENCIAMENTO ÁGIL DE PROJETOS}

O GAP apresenta uma série de particularidades que o difere dos métodos tradicionais de Gerenciamento de Projetos (GP). Uma delas é o uso de iteração, que segundo Highsmith (2004), pode ser entendido como: "produzir um resultado em um determinado período de tempo pré-definido, de forma que este resultado possa ser em seguida". 
Outra é o papel de destaque que o cliente, sendo inserido na equipe de projetos e com a responsabilidade de guiar o desenvolvimento por meio da priorização e validação das entregas, o que cria a necessidade de se atuar ativamente para que exista um entendimento compartilhado entre a ele e os demais membros da equipe de projetos (CHAN; TONG, 2009).

Entretanto, a principal diferença que impacta na GC e no aprendizado organizacional é que o GAP opta pela redução do uso do conhecimento explícito em detrimento de um uso maior dele na sua forma tácita (CHAU; MAUER; MELNIK, 2003; YANZER RIBEIRO; CABRAL; NOLL, 2014) o que têm implicações nos meios de comunicação, fatores humanos e sociais, ciclo de desenvolvimento e artefatos, ferramentas para a GC e formas de representação do conhecimento (YANZER RIBEIRO; CABRAL; NOOL, 2014).

Essas diferenças estão diretamente ligadas às mudanças no paradigma do GP tradicional para o GAP. O primeiro aborda o conhecimento como algo estático, sendo possível de ser antecipado e totalmente disponibilizado antes do início do projeto, ou seja, o foco estaria em se fazer um planejamento prescritivo e linear (AHERN; LEAVY; BYRNE, 2014b).

Já em projetos complexos ou instáveis, passíveis de grandes mudanças, como os em que o GP tradicional apresenta limitações e o GAP se propõe em atuar, parte-se do princípio da incapacidade de se antecipar as necessidades, uma vez que as incertezas são muito acentuadas, abordando o conhecimento como sendo dinâmico e experimental (AHERN; LEAVY; BYRNE, 2014b).

Logo, o GAP utiliza o desenvolvimento iterativo e incremental para enfrentar essas incertezas, aumentando o seu conhecimento a cada iteração. Para que essa dinâmica seja facilitada, segue-se um dos princípios do manifesto ágil: "em intervalos regulares, a equipe reflete em como ficar mais efetiva, então, se ajustam e otimizam o seu comportamento" (BECK et al, 2001), por meio das reuniões retrospectivas..

\section{REUNIÕES RETROSPECTIVAS}

A reunião retrospectiva tem por finalidade contribuir para a melhoria contínua e fornecer um caminho para engajar os membros de uma equipe na melhoria dos seus processos em resposta direta a problemas que eles enfrentaram (DAVIES; SEDLEY, 2009; RUBIN, 2012). Ela é a última atividade da iteração e deve ajudar a equipe a explorar as seguintes questões: "Quais foram as principais ideias que tivemos na última iteração? Quais áreas nós desejamos melhorar? Quais ideias de melhoria podem ser executadas na próxima iteração?" (DAVIES; SEDLEY, 2009).

O tempo para a sua execução é delimitado para evitar que a equipe de projetos se alongue demasiadamente procurando pela inalcançável perfeição (SCHWABER, 2004). Durante sua execução, pode ser gerado um backlog de ideias, que consiste em uma lista melhorias sugeridas pela equipe, para serem executadas nas próximas iterações (RUBIN, 2012).

A literatura não traz um consenso com relação à forma de execução das reuniões retrospectivas, contudo, qualquer que seja a dinâmica utilizada é fundamental que ela seja tratada como um ritual imprescindível, se tornando um período ao final da iteração no qual as pressões de tempo que impactam na GC na execução do GAP sejam minimizadas, propiciando oportunidades para o aprendizado e melhorias contínuas, devendo ser aproveitada de forma ativa para realização de atividades deliberadas de GC no projeto. 


\section{MÉTODO}

Neste trabalho foi utilizado como método de pesquisa o estudo de caso, definido por Yin (2009) como sendo uma investigação empírica profunda de um fenômeno contemporâneo no seu real contexto, em que os limites entre eles não estão bem definidos. Nesses estudos, o pesquisador tem um restrito grau de envolvimento e interação com o objeto de estudo, e dentre seus principais benefícios estão a possibilidade de desenvolvimento de novas teorias e aumentar o entendimento sobre eventos reais e contemporâneos (MARTINS, 2010).

Desse modo, os estudos de casos foram utilizados para descrever e entender (EISENHARDT, 1989; STUART et al., 2002) como as reuniões retrospectivas do GAP se relacionam com a GC em projetos, além de permitir reflexões que juntamente com outros estudos futuros possam estender a possibilidade do seu uso para outros tipos de projetos.

Foram seguidas as fases propostas por Yin (2009) e Voss (2002): mapeamento da literatura, seleção dos casos, planejamento dos casos (construção do questionário e protocolo) e condução do estudo (coleta e análise).

A coleta de dados foi realizada durante a interação com o objeto de estudo, seja por meio das entrevistas, seja por meio do acompanhamento das reuniões retrospectivas e da análise de documental. Vale ressaltar que o acompanhamento se deu apenas na forma de expectador, sem a participação do pesquisador nas discussões.

Durante as entrevistas, múltiplos respondentes foram consultados, para evitar vieses devido a diferentes interpretações e pontos de vista (VOSS et al., 2002). Primeiramente, foi realizada uma entrevista com os responsáveis pelos projetos da empresa e com os envolvidos nas iniciativas de GC, a fim de entender os processos e práticas utilizadas pela organização. Posteriormente, foram selecionados projetos que serviram de caso e realizadas entrevistas semiestruturadas com os líderes a alguns membros das equipes, assim como 0 acompanhamento de reuniões retrospectivas na situação de observador.

Devido ao contrato de sigilo e confidencialidade, as entrevistas não foram gravadas, contudo, foram anotadas as informações relevantes e construída uma narrativa da entrevista, a qual foi enviada para os participantes e validada. Da mesma forma, após a realização das análises, foram realizadas reuniões com os participantes para a confirmação da verossimilhança com a realidade.

\section{DESCRIÇÃO DOS CASOS E DISCUSSÕES}

Nesta seção, é realizada uma breve descrição da empresa e dos casos estudados, assim como realizadas algumas discussões a seu respeito notadamente no que se referem às reuniões retrospectivas acompanhadas.

\subsection{Empresa $\beta$}

A empresa Beta $(\beta)$ tem suas atividades na área de Tecnologia da Informação e sua matriz está situada no interior do estado de São Paulo. Ela atua em todas as etapas do desenvolvimento de aplicativos para dispositivos móveis, desde o planejamento e idealização, passando pelo desenvolvimento, integração, suporte e manutenção. Na época dos estudos contava com cerca de quarenta e cinco colaboradores, sendo trinta e cinco desenvolvedores e outros dez distribuídos entre designers, especialistas em testes e recursos humanos. Ela também possuía cinco projetos em andamento 
A estrutura organizacional da empresa é projetizada, contando com um conselho composto por cinco membros, sendo três sócios e dois conselheiros externos com vasta experiência de mercado (cerca de 30 anos de atuação profissional cada). Abaixo deste conselho estão às diretorias assumidas pelos três sócios e, por fim, as equipes autogeridas.

A empresa $\beta$ adota o Scrum como método de gerenciamento de seus projetos, os quais se dividem, segundo o entrevistado, em dois segmentos: desenvolvimento de produtos (advindos das percepções das necessidades de mercado pelos seus conselheiros e equipes) e prestação de serviços (desenvolvimento de soluções personalizadas para clientes). Os rituais do Scrum são adotados conforme preconizado na literatura, com destaque para: daily, planning, retrospective e demo. Neste artigo, o foco apenas é a na reunião retrospectiva (retrospective).

\subsubsection{Projeto $\beta 1$ e sua Reunião Retrospectiva}

O projeto $\beta 1$ se tratava de um desenvolvimento interno, com a ideia advinda dos conselheiros externos a empresa e já com a negociação com um cliente em potencial. Consistia em uma solução para o mercado financeiro e bancário e o cliente em potencial possuía sua matriz em outro país, desse modo, as regras do desenvolvimento seguiam as particularidades do país de destino.

Apesar da adequação à realidade regional, o potencial cliente e a empresa $\beta$ ainda não haviam fechado o negócio, o que introduziu algumas particularidades. A principal dela se relacionava a participação do Product Owner (POs), sendo suas atribuições divididas por seis pessoas, formando um grupo de POs que muitas vezes possuía divergências e problemas na comunicação na opinião dos entrevistados.

A reunião retrospectiva acompanhada aconteceu no dia posterior a review e teve duração de cerca de uma hora e quinze minutos. Ela aconteceu em uma sala de reuniões, com a equipe sentada em e uma colaboradora que participava de forma virtual, via videoconferência.

Desse modo, além do pesquisador e do Scrum Master (SM), seis membros da equipe de projetos participaram da reunião, sendo dois desenvolvedores Android, dois responsáveis pelo backend, uma analista de testes e uma pelo design (que era dedicada em tempo parcial a equipe). Esse ritual foi conduzido por um membro da equipe e sob a justificativa de contribuir com a formação, acontecendo um rodizio membros a fim de desenvolver habilidades gerenciais.

Inicialmente, foi dado um tempo para cada membro da equipe escrever em uma nota autoadesiva até três fatos que consideraram negativos na sprint anterior. Depois de findado esse tempo, iniciou-se, a exposição desses pontos pelos colaboradores, com a fixação da nota autoadesiva na parede ao seu término. Por diversas vezes, após a exposição, outros membros perguntam mais informações sobre os pontos, para esclarecê-los melhor e algumas ideias e pequenas discussões eram realizadas de forma produtiva, evidenciando trocas tácitas e conhecimentos.

Durante a reunião verificou-se que a realização de críticas e sugestões. Em diversas ocasiões os colaboradores citavam as dificuldades e, para ilustrar, davam exemplos do ocorrido durante a iteração, inclusive fazendo uma autocrítica em alguns momentos. Exemplo disso ocorreu quando um colaborador apontou dificuldades na comunicação da equipe e afirmou que ele mesmo não repassava as informações em alguns momentos "por não ter tempo hábil, esquecer ou por achar que não eram importantes". 
Foi mencionado pelos colaboradores que a equipe procurava usar esse ritual como forma de melhoria contínua, inclusive, houve a incorporação de um membro adicional à equipe de projetos inicial pela identificação de sobrecarga em uma função específica, diagnosticada em uma retrospectiva.

Ao término de todas as exposições, os pontos comuns foram agrupados, todas as críticas e sugestões relembradas e realizada a votação de qual ponto deveria ser melhorado durante a sprint, sendo possível escolher apenas uma opção. Ao final, dois pontos tiveram votação próxima e, como foram considerados de simples execução, ambos foram selecionados para melhoria. Esse procedimento visava priorizar as atividades.

As notas autoadesivas foram armazenadas para sprints futuras. Segundo o entrevistado, ele elas são transcritas para um documento de texto, com um template que ele mesmo criou, separando pontos positivos de negativos, que é consultado antes de uma nova retrospectiva.

Após a apresentação dos pontos negativos foi realizada a dos positivos, desta vez, sendo anotada em notas autoadesivas de outra cor e realizada a exposição no sentido inverso. Durante essa apresentação, os comportamentos positivos eram estimulados e, aqueles que ainda não estavam satisfatórios, mas tinham sido melhorados, recebiam elogios e eram incentivados a continuarem a serem trabalhados.

Desse modo, verificou-se que a retrospectiva em $\beta 1$ conseguia contribuir para tornar a equipe mais efetiva. Como principais destaques estão a realização de uma reunião com um procedimento sistemático e com a dedicação de um intervalo de tempo exclusivo para ela, realmente blindando a equipe do impacto da pressão do tempo. Na visão do Scrum Master e dos membros da equipe entrevistados, "a retrospectiva é um dos rituais mais importantes", contribuindo para a troca de conhecimentos entre os membros da equipe e para o "aprendizado de como trabalhar em equipe", visto que "cada equipe de projetos é diferente".

A pouca documentação gerada se baseava nos pontos elencados, o que dificulta a GC interprojetos. Contudo, as ricas trocas de experiências e aprendizados combinadas com a autorreflexão dos membros e do grupo como um todo constituiu um importante momento para a criação e compartilhamento de conhecimentos tácitos. Segundo os membros da equipe entrevistados, em todos os projetos ágeis "demora um tempo até a equipe engrenar" e a reunião retrospectiva "contribui muito para o entrosamento dos membros".

\subsubsection{Projeto $\beta 2$ e sua Reunião Retrospectiva}

O projeto $\beta 2$ tratava do desenvolvimento de um aplicativo para um cliente externo que é integrado com um relógio. A equipe operacional do projeto era composta por seis membros, sendo dois desenvolvedores Android, dois desenvolvedores IOS, um responsável pela qualidade e um designer. Uma particularidade desse projeto era que o SM não estava dedicado em tempo integral, cuidando simultaneamente de mais um desenvolvimento, além da manutenção de dois outros.

Uma das grandes dificuldades de $\beta 2$ era que o relógio era fabricado na China e possuía, na visão dos desenvolvedores, uma série de bugs que dificultavam ou impediam a implementação das estórias do cliente. Outra dificuldade apontada neste sentido foi com relação à zona do tempo. Como os fusos horários do Brasil e China são bastante diferentes, durante o trabalho das equipes brasileiras era a folga dos chineses e vice versa.

Foi acompanhada uma reunião retrospectiva. Ela foi facilitada pelo analista de testes, tanto como forma de treinamento dos colaboradores nos rituais GAP, como para preparar a equipe 
para as férias do SM que estavam previstas. O encontro aconteceu na sala de reuniões da empresa que contava com uma tela e um quadro visual, além da mesa central e cadeiras. Os membros da equipe se sentaram em semicírculo, voltados para o facilitador e para o quadro visual. Participaram da reunião, além do pesquisador, o Scrum Master e seis membros operacionais.

Inicialmente, o facilitador dividiu o quadro em duas metades: uma com o título "o que foi bom" e a outra com "precisamos melhorar". O SM interrompeu a reunião neste momento para esclarecer que não escrevem pontos positivos e negativos, pois nem sempre os pontos negativos podem ser melhorados, evitando induzir a uma interpretação depreciativa.

Então, foi pedido para que os membros da equipe escrevessem em uma nota autoadesiva até três pontos que considerassem positivos durante a sprint. Após um período para que eles pensassem e preenchessem cada membro do semicírculo começou a falar os pontos e explicando-os, de forma ordenada, iniciando em uma ponta e terminando em outra, sendo que o SM também tinha o direito de preenchimento. $\mathrm{O}$ facilitador escrevia esses pontos no quadro, sempre questionando para verificar o entendimento correto e era o último a falar.

Um ponto citado por vários membros foi que a equipe tinha melhorado seu uso do Scrum e, por isso, conseguiu finalizar estórias com funcionalidades completas no começo, meio e fim da sprint.

Durante a exposição dos pontos positivos, outros membros que concordassem com o ponto ou se lembravam de exemplos ilustrativos, comentavam e traziam essas lembranças para enriquecer as discussões. Ao término da exposição, todos os membros tinham direito a votar em três pontos que considerassem mais importantes, a fim de que fossem "destrinchados" e melhor discutidos em um momento futuro da reunião.

Esse procedimento era adotado tanto para pontos fortes que deveriam manter como nos que deveriam melhorar, pois o mesmo ponto poderia estar na mesma coluna com facetas diferentes. Por exemplo, a equipe poderia ter um aspecto positivo, que seria o "entrosamento e abertura para críticas e conversas", contudo, também estar no que precisa ser melhorado com relação à "comunicação de alterações importantes em tempo hábil para não impactar outras atividades".

Um ponto interessante é que os participantes raramente votavam nos três pontos que tinham sugerido o que mostra que a exposição e conversa sobre eles causava algum alinhamento e mudança de opinião ou, pelo menos, o entendimento que alguns pontos apontados não eram prioritários.

Terminada a votação, um período foi estabelecido para que cada membro escrevesse, em uma nota adesiva de outra cor, três pontos que acreditavam que precisava melhorar, sendo esses depois expostos no mesmo formato dos pontos fortes. Um aspecto positivo é que, além de pontos gerais, alguns membros também trouxeram autorreflexões. Em alguns pontos mais polêmicos e impactantes, a equipe realizou discussões rápidas, compartilhando modelos mentais, opiniões, sugestões, dentre outros.

Após a exposição e discussão, os membros votaram nos três principais, selecionando os mais votados para serem "destrinchados" e melhor debatidos. O facilitador então apagou o quadro, exceto os títulos, e reescreveu os três principais pontos positivos e a melhorar.

Cada um deles foi repassado em detalhe, e conforme os participantes falavam suas impressões o facilitador os escrevia. Os comportamentos positivos eram estimulados e os a melhorar eram debatidos, procurando encontrar as suas causas e realizadas sugestões de melhoria. 
A documentação da retrospectiva aconteceu em dois momentos: o primeiro foi fotografar o quadro com todos os pontos que foram bons e que precisam melhorar e o segundo foi posterior as atividades "destrinchadas".

Após as decisões tomadas, por consenso ou votação, as telas dos sprints anteriores foram recuperadas, e escritas no quadro todos os pontos selecionados para melhorias e continuidade. Como última atividade, a equipe repassou todos eles verificando se os considerados positivos continuaram satisfatórios e os com necessidade de melhoria evoluíram.

Em caso de discordância entre os membros da equipe o ponto era votado para saber, se na média, ele tinha melhorado ou não, sendo as ressalvas anotadas. Dos doze pontos anteriores considerados positivos apenas dois tiveram pequenas quedas. Vale ressaltar que muitos pontos positivos de destaque se mantiveram em várias sprints, como o entrosamento da equipe. Foi realizada uma breve discussão sobre os motivos da piora e dadas sugestões de como melhorar. Dos doze pontos "a melhorar", quatro possuíram quedas e foram discutidas soluções para voltar a trazê-los a patamares satisfatórios.

Percebe-se, que assim como em $\beta 1$ a sistemática de reunião combinada com um intervalo exclusivo para a mesma contribuiu positivamente para a melhoria da eficiência e para uma rica troca de conhecimentos. Apesar de parecidas, a dinâmica de $\beta 2$ se diferencia pelo "destrinchamento" dos pontos e pela recuperação e monitoramento dos ganhos das retrospectivas anteriores.

Esses diferenciais contribuíam para um melhor entendimento e mais amplo de cada um dos pontos selecionados, inclusive notando que mesmo com aspectos positivos o mesmo ponto poderia ser melhorado em outras frentes, aumentando o entendimento de todos sobre os problemas. Já o monitoramento e recuperação histórica permitia a busca de uma melhoria sustentável e de que as deficiências fossem trabalhadas até serem supridas permanentemente.

Tanto o SM quanto a equipe apontaram esse ritual como fundamental e imprescindível para o bom andamento dos projetos ágeis e afirmaram "que todos aprendem muito com ele". Em entrevista posterior com o SM foi afirmado que, além de pontos técnicos e de trabalho em equipe, as retrospectivas "contribuem para o aumento do conhecimento a cerca dos métodos ágeis e do que está por traz de cada atividade" e, desse modo, "quanto mais a equipe reflete e ganha esse entendimento, mais fácil fica a autogestão".

\section{CONCLUSÕES}

Os casos estudados permitiram verificar a importância das reuniões retrospectivas para a boa utilização dos métodos de GAP. Além da melhoria da eficiência da equipe, essas reflexões permitem o aprendizado sobre como trabalhar em grupo, o que varia para cada formação de equipe, e para o melhor entendimento as práticas e rituais do GAP, contribuindo para uma melhor autogestão, que é fundamental para a utilização desses métodos.

Apesar da maior parte das discussões não se referirem a aspectos técnicos, as retrospectivas acabam por também gerar aprendizados nesse sentido, especialmente com relação a visão sistêmica e integração de áreas diferentes .

Nos casos estudados ficou clara a necessidade de um período próprio e exclusivo para a reflexão, minimizando os efeitos da pressão de tempo e possibilitando o melhor foco. Também foi evidenciada a importância da adoção de uma sistemática de reunião e da seleção de poucos e prioritários pontos de trabalho por vez. 
O ritual de retrospectivas está diretamente relacionado ao conceito de melhoria contínua, e como tal, para ser efetivo, tem que ser planejado, realizado, controlado e analisado, buscandose uma melhoria perene e sustentável, o que ficou claro no projeto $\beta 2$.

Por fim, vale ressaltar que apesar da significativa contribuição das reuniões retrospectivas para a gestão do conhecimento intraprojetos, a redução e simplificação da documentação continuam fazendo com a que GC interprojetos seja prejudicada. Algumas estratégias podem ser adotadas para minimizar esses efeitos: a criação de documentos específicos em momentos cruciais do projeto, seguindo a linha das lições aprendidas dos projetos tradicionais, ou o estímulo da criação de comunidades de práticas e outras formas de interação e trocas de conhecimentos tácitos entre os membros de diferentes equipes de projetos. Atuações híbridas com a combinação dessas duas linhas também podem potencializar os resultados esperados.

Como estudos futuros, propõe-se a realização de novos estudos de casos em outras empresas, verificando dinâmicas diferentes e o impacto delas na GC, assim como a realização de levantamentos estatísticos que possam analisar o impacto de aspectos das reuniões retrospectivas nos diferentes processos de GC. Também seria importante a realização de um estudo de caso longitudinal que contribuísse para o melhor entendimento acerca dos benefícios das reuniões retrospectivas no decorrer do ciclo de vida do projeto, assim como da realização de pesquisações para estudar a adoção e melhoria das dinâmicas das reuniões retrospectivas.

\section{REFERÊNCIAS}

AHERN, T.; LEAVY, B.; BYRNE, P. J. Knowledge formation and learning in the management of projects: a problem solving perspective. International Journal of Project Management, v. 32, p. 1423-1431, 2014a.

AHERN, T.; LEAVY, B.; BYRNE, P. J. Complex project management as complex problem solving: A distributed knowledge management perspective. International Journal of Project Management, v. 32, p. 1371-1381, 2014b.

AMRITESH; MISRA, S. C. Conceptual modeling for knowledge management to support agile software development. The knowledge engineering review, v. 29, n. 4, p. 496-511, 2014.

BAKKER, R. M.; CAMBRÉ, B.; KOLAAR, L.; RAAB, J. Managing the project learning paradox: A set-theoretic approach toward project knowledge transfer. International Journal of Project Management, v. 29, n. 5, p. 494-503, 2011.

BECK, K. et al. Manifesto for agile software development. Disponível em <http://www.xprogramming.com/publications/dc9810cs.pdf> Acesso em 16 jan. 2017, 2001.

BRESNEN, M.; EDELMAN, L.; NEWELL, S.; SCARBROUGH, H.; SWAN, J. Social practices and the management of knowledge in project environments. International Journal of Project Management, v. 21, p. 157-166, 2003.

CHAN, F. K. Y.; THONG, J. Y. L. Acceptance of agile methodologies: A critical review and conceptual framework. Decision Support Systems, v. 46, p. 803-814, 2009.

CHAU, T.; MAURER, F.; MELNIK, G. Knowledge sharing: agile methods vs. Tayloristic methods. In 12th IEEE Workshop on Enabling Technologies: Infra- structure for Collaborative Enterprises (WET ICE 2003). IEEE Computer Society, 2003.

DAVIES, R.; SEDLEY, L. Agile Coaching. The Pragmatic Bookshelf. Raleigh, North Caroline, 2009. 
DE SOUZA; K, C.; EVARISTO; J. R. Project management offices: a case of knowledgebased archetypes. International Journal of Information Management. V. 26, n. 5, p. $414-423$, 2006.

EISENHARDT, K. M. Building Theories from Case Study Research. Academy of Management Review, v. 14, n. 4, p. 532-550, 1989.

FONG, P. S. W. Can we learn from our past? Managing knowledge and learning within and across projects. In: BECERRA-FERNANDEZ, I.; LEIDNER, D., Knowledge Management: An Evolutionary View. Advances in Management Information System. New York, 2008.

HIGHSMITH, J. Agile Project Management: creating innovative products. Addison-Wesley: Boston, 2004.

LINDNER, F.; WALD, A. Success factors of knowledge management in temporary organizations. International Journal of Project Management, v. 29, p. 877-888, 2011.

MARTINS, R. A. Abordagens Quantitativa e Qualitativa. In: CAUCHICK, P. A. M., Metodologia em pesquisa em engenharia de produção e gestão de operações. Campus: São Paulo, 2010.

PROJECT MANAGEMENT INSTITUTE - PMI. Guia PMBOK: Um guia do conjunto de conhecimentos do gerenciamento de projetos. Pennsylvania: Project Management Institute, 4th. ed, 2008.

RUBIN, K. S. Essential Scrum: A pratical guide to the most popular agile process. AddisonWesley: Upper Saddle River, 2012.

SCHWABER, K. Agile Project Management with SCRUM. Microsoft Press: Washington, 2004.

STUART, I.; McCUTCHEON, D.; HANDFIELD, R.; McLACHLIN, R.; SAMSON, D. Effective case research in operation management: a process perspective. Journal of Operations Management, v. 20, p. 419-433, 2002.

SWAN, J.; SCARBROUGH, H.; NEWELL, S. Why don't (or do) organizations learn from projects? Management Learning., v. 41, n. 3, p. 325-344, 2011.

VOSS. C.; TSIKRIKTSIS, N.; FROHLICH, M. Case research in operation management. International Journal of Operation \& Production Management, v.22, n. 2, p. 195-219, 2002.

WENGER, E. Communities of Practice: Learning, Meaning, and Identity. Cambridge University Press, Cambridge, UK (Orig. 1998), 2001.

YANZER CABRAL, A. R.; RIBEIRO, NOLL, R. P. Knowledge Management in Agile Software Projects: A systematic review. Journal of Information \& Knowledge Management, v. 13, n. 1, p. 1-37, 2014.

YIN, R. K. Case study research: design and methods (4ed.). Trousand Oaks: SAGE Publications, Inc., 2009. 